\title{
Editor's/Publisher's Disclaimer
}

Parts of the papers presented here have been used as camera-ready copy as submitted by the authors; when retyped, they have been edited by the editorial staff only to the extent considered necessary for the assistance of an international readership. The views expressed and the general style adopted remain, however, the responsibility of the named author(s). Great care has been taken to maintain the accuracy of the information contained in the issue. However, neither the publisher nor the editors can be held responsible for errors or for any consequences arising from the use of information contained herein.

The use in this publication of particular designations of countries or territories does not imply any judgement by the publisher or editors as to the legal status of such countries or territories, of their authorities or institutions, or of the delimination of their boundaries.

Some of the names of products referred to in this publication may be registered trademarks or proprietary names, although specific reference to this fact may not be made; however, the use of a name with designations must not be construed as a representation by the publisher or editors that it is in the public domain. In addition, the mention of specified companies or of their products or proprietary names does not imply an endorsement or recommendation on the part of the publisher or editors.

The authors were responsible for obtaining the necessary permission to reproduce copyright material from other sources. With respect to the publisher's copyright, material appearing in this publication prepared by individuals as part of their official duties as government employees is only covered by this copyright to the extent permitted by the appropriate national regulations. 